Ramirez-Valenzuela, A., Gamarra-Diaz G. G. and Erazo-Rondinel, A. (2021). "Proposal Model for the Management of Construction Based on Flows - A Complex Adaptative System." Proc. $29^{\text {th }}$ Annual Conference of the International Group for Lean Construction (IGLC29), Alarcon, L.F. and González, V.A. (eds.), Lima, Peru, pp. 859-869, doi.org/10.24928/2021/0205, online at iglc.net.

\title{
PROPOSAL MODEL FOR THE MANAGEMENT OF CONSTRUCTION BASED ON FLOWS - A COMPLEX ADAPTIVE SYSTEM
}

\author{
André Ramírez-Valenzuela ${ }^{1}$, Gilberto G. Gamarra-Díaz ${ }^{2}$, and Andrews A. Erazo- \\ Rondinel $^{3}$
}

\begin{abstract}
Project management models understand construction as an ordered and simple phenomenon without considering its complexity, dynamism, and high variability. Also, they are models adapted from other sectors such as manufacturing and information technology (IT). This research aims to be a new trend for developing management models, typical of construction, from complexity. The following points are considered, as a first step, to this new trend of holistic construction management: 1 . Generate and manage flows, which are the main components for the production in construction-beginning to understand each flow, its importance, and its properties; and 2. Manage complexity in construction projects by understanding and promoting the production system as a Complex Adaptive System (CAS) that requires organizations of action and learning as an Operational Excellence Organization. The proposed model offers a holistic analysis of the system considering flow management as a basis. It relates the project management approaches proposed by Bertelsen and Koskela (2005), the Value - Flow - Operation (VFO) model proposed by Bertelsen (2017), and the seven preconditions of Koskela (2000), except for external conditions by which these are a threat of flow, but do not flow in the proposed model.
\end{abstract}

\section{KEYWORDS}

Complexity, flow integration, value, management, complex adaptive system (CAS).

\section{INTRODUCTION}

The construction sector is one of the engines of the economy and a significant generator of employment. Civil works such as hospitals and schools solve the needs of the towns.

\footnotetext{
CEO of Sonder Hub, Lima, Peru, raramirezv@ uni.pe, orcid.org/0000-0003-4585-9946

Civil Engineering, Faculty of Civil Engineering, Universidad Nacional de Ingeniería, Lima, Peru, gilberto.gamarra.d@uni.pe, orcid.org/0000-0002-1469-7342

3 Teaching Assistant, Faculty of Civil Engineering, Universidad Nacional de Ingeniería,, Lima, Peru aerazor@uni.edu, orcid.org/0000-0002-5639-573X
} 
Internally, construction projects have unreliable schedules, additional costs generated by a low initial engineering or design study, continuous variations in scope, and little concern for the maintenance or post-construction stage. All the above is reflected in works with long, backward times, cost overruns, and a short time of useful life, generating dissatisfaction in the client and final user.

Accepting that construction is a complex, dynamic and non-linear phenomenon shows new management approaches that allow obtaining the desired results (Bertelsen 2003a; Bertelsen 2003b). Own management for the construction from a complexity perspective can be the solution with action and learning organizations. The paper aims to open a holistic management research field under construction and encourage developing new management models typical of this sector, considering its characteristics. Four objectives are defined: (1) Analyze the complex nature of construction. (2) Integrate existing flows in construction. (3) Analyze the importance of flow management in construction. (4) Analyze the management of people in construction.

\section{METHODOLOGY}

This research begins by presenting the models' evolution that seeks to describe the production system under construction. If someone wants to manage a project, they must first understand how the production system works. The models presented have not received the necessary importance or have not been understood in their entirety, this being the main point that hinders the project management under construction. Next, complexity and the construction of a complex system are described - an overview of its nature. The evolution of project management is explained before presenting the model for the management of construction based on flows, as an initial proposal of holistic construction management from a complexity perspective. Finally, the Complex Adaptive System (CAS) concept is presented to manage complexity from an action and learning organization, such as an Operational Excellence Organization. We are increasingly convinced that an organization that manages people and knowledge manages complexity.

\section{PRODUCTION CONSTRUCTION SYSTEM}

"The production system under construction is a set of operatively interrelated parts, dynamic, of which it is important to consider its global behaviour" (Ramirez 2014, p.2829). Representing this system has been a complete challenge as an essential step to carry out an adequate study and analysis of it. Some authors, seeking to explain the nature of the production system, proposed models that evolved.

\section{DUAL MODEL}

Traditionally, construction has been seen and modelled as a series of conversion activities; the products (outputs) result from the transformation of raw materials (inputs). The main concern was to make conversions increasingly efficient (Koskela 1992). Based on the lean production philosophy, this thought was criticized by himself and proposes identifying and eliminating non-conversion activities in construction and establishing a dual model where 
non-conversion activities or flow activities must be eliminated or reduced to the maximum (Kraemer et al. 2007).

\section{TRANSFORMATION - VALUE - FlOW (TFV) MODEL}

From the dual model, flows received more importance. Flows are generated in the interaction of the production system's components. However, the transformation $(\mathrm{T})$ and the flows (F) are differentiated, and the value (V) is spoken of; these three are seen independently. Subsequently, Koskela (2000) proposes the TFV model, grouping these three aspects or sub-theories of production, $(\mathrm{T})$ as added value, $(\mathrm{F})$ as non-conversion activities, and (V) under the concept of reflecting and satisfying the needs of customer or end-user.

\section{FLOW NETWORK MODEL}

For Shingo, flow is a chain of events related by a sequence to achieve a goal, and the production system is a network of process and operations flows. "Processes are flows of objects, represent the progress of a product along a production line and operations are a temporal and spatial human flow that consistently focuses on the worker" (Shingo 1988, p.4-5).

In construction, the process can be understood as the project's evolution and operations as the workers' work or equipment (Kalsaas and Bølviken 2010).

\section{VALUE - FlOW - OPERATION (VFO) MODEL}

Koskela et al. (2007) propose a new development of TFV theory, orienting it with the vision of Shingo (1988) in its flow network model, arguing that to manage construction. The three sub-theories of the TFV model must be considered and integrated: (T) Transformation, work-oriented (flow of subjects or operations), observing the interaction of labor and machinery with the materials, and workflow. (F) Flow, oriented to spatial and temporal movements of materials and information exchange; and (V) Generation of Value. Oriented to look at the process of designing and manufacturing products to satisfy the customer's needs (flow of objects or processes), see Figure 1.

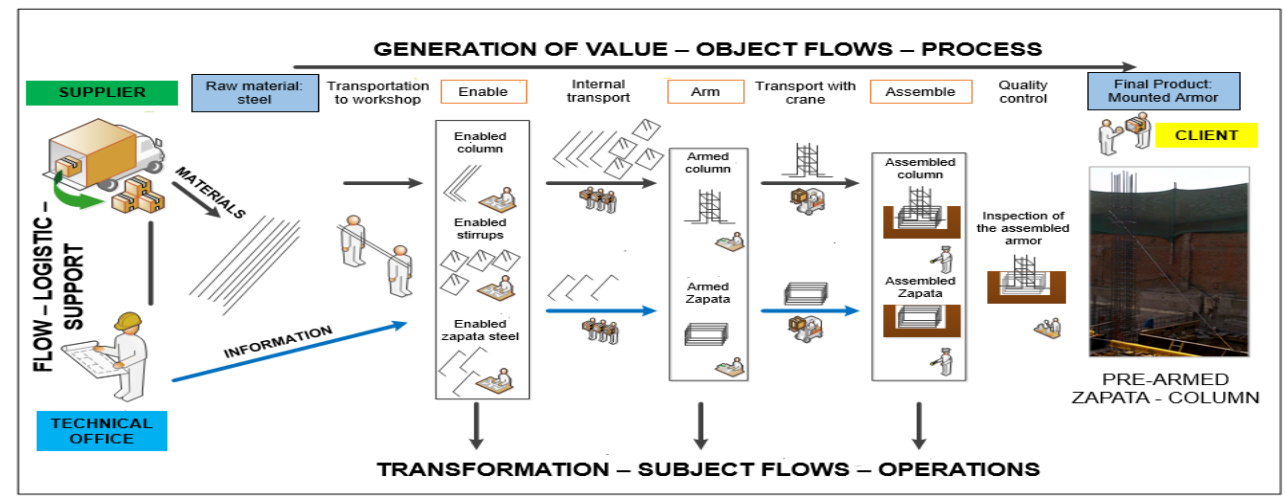

Figure 1: Vision of the Value - Flow - Operation (VFO) production model: Case Prearmed Steel in Zapata-Column (Adapted from Ramirez, 2014) 
This new development substantially improved the TFV theory, which differentiates transformation and value mainly. It was not called VFO until the publication of the article "Transformation-Flow-Value as a Strategic Tool in Project Production" by Bertelsen, and Bonke (2011), where they mentioned that value is the main objective of managing flows and executing operations (Value - Flow - Operation). Later Bertelsen (2017) already uses the name VFO in his book "The Unruly Project."

\section{COMPLEXITY}

\section{COMPLEXITY IN CONSTRUCTION}

The construction is a complex, dynamic and non-linear system, often on the edge of chaos where chaos "refers to a restricted set of phenomena that evolve in predictable unpredictable ways" (Bertelsen 2003a, p.3-4). It is complex from the product and the nature of the design process, which generates problems by not having agreed solutions, where it is not even clear that the customer want to get to the end, which leads to defining the conditions of satisfaction in parallel with the solutions (Bertelsen 2003a; Bertelsen and Emmitt 2005; Macomber and Howell 2003; Mossman 2017).

The dynamic nature is observed in the uncertainty present in the flows, affecting the execution of tasks (Bertelsen 2017; Hamzeh et al. 2016; Bertelsen et al. 2006) and the participants in the project's materialization due to its temporary nature.

While non-linearity reflects the unpredictable, the plans carried out represent a very idealized linear image of what should be executed, predictably, not considering the interdependence of the operations to be executed (Bertelsen 2003a; Koskela 2000; Koskela 2004; Hamzeh et al. 2016).

\section{Perspectives of Complexity in Construction}

Bertelsen (2003a) suggests analyzing the complexity of construction from three perspectives: 1. The complex and dynamic construction project. The management must give flows prime importance to ensure that the tasks have everything necessary to be executed (Bertelsen et al. 2006, Gamarra 2018); 2. The construction industry, fragmented "by increasingly common subcontracting practices, where the economic issue often prevails, not taking into account the complexity it generates, often reflecting problems of planning and control in projects" and, 3- the social aspects people should give importance. The project's success will depend on the cooperation, communication, and commitment that develops in it (Gamarra 2018).

\section{PROJECT MANAGEMENT IN CONSTRUCTION}

Koskela and Howell (2002) show that traditional construction management follows the Project Management Institute's good practices (PMI) based on the conversion model, presenting significant deficiencies from its theoretical base. Therefore, they propose new approaches based on the TFV model, see Table 1. 
Table 1: Construction Project Management Approaches (Adapted from Table 1 and 3 in Koskela and Howell 2002)

\begin{tabular}{cccc}
\hline \multicolumn{2}{c}{ Production model } & $\begin{array}{c}\text { Conversion model } \\
\text { (PMI) }\end{array}$ & $\begin{array}{c}\text { Model TFV } \\
\text { ( Koskela and Howell (2002). }\end{array}$ \\
\hline Management & Elanning & Operational planning. & Planification and organization. \\
& Control & $\begin{array}{c}\text { Standard } \\
\text { performance. }\end{array}$ & $\begin{array}{l}\text { Bidirectional communication. } \\
\text { Identify errors. Proposal for } \\
\text { improvement and learning. }\end{array}$ \\
\hline
\end{tabular}

The management proposed presents new and broader approaches, leaving aside the old view of construction, which can be organized, planned, and managed in a predictable way (Bertelsen 2003a), but still does not manage the construction in its nature.

\section{PROJECT MANAGEMENT IN CONSTRUCTION WITH A COMPLEXITY APPROACH}

Bertelsen and Koskela (2005), from the approaches to project management proposed by Koskela and Howell (2002), based on their experiences and the perspectives of the complexity of construction presented by Bertelsen (2003a), propose to manage construction projects under the following complexity approaches:

\section{Management as Flow and Value Generation}

One of the first steps to properly manage a project is to identify the client's value proposition. Many, this being considered a problem "without solution" reflected, for example, in constant changes of design (Gamarra 2018). Studies by Drevland and Tillmann (2018) and Erikshammar et al. (2010) examine the value. At the same time, Bertelsen and Emmitt (2005) study the client as a complex system.

On the other hand, the flow management must be done from the beginning so that when reaching the operational level (figure 4), there are no disorder, ignorance, and problems that prevent the execution of tasks on their scheduled dates (Bertelsen and Koskela 2005, Gamarra 2018, Hamzeh et al. 2016, Koskela 2004, Kraemer et al. 2007).

\section{Management as Team BUILding}

The dynamism present in the construction is reflected in the temporary and transitory nature of the people. They mixed different cultures, thoughts, opinions, and others., which often were not taken into account despite the significant influence in the workplace. Establishing a spirit of teamwork where cooperation, collaboration, communication, and trust among all people prevail strengthens the way to achieve the project's objectives (Bertelsen and Koskela 2005, Gamarra 2018, Plenert 2018, Mossman 2017).

\section{Management as Language/Action Perspective}

The erroneous thought of considering that the execution of work will be carried out by the simple fact of issuing an order often leads not obtaining the desired result. Moreover, if 
people want to be sure that this happens, people must control it exhaustively (Gamarra 2018, Koskela and Howell 2002).

This approach must follow the execution model based on the flow of commitments, which arises from the Theory of Linguistic Action, to guarantee a greater probability of compliance (Gamarra 2018, Macomber and Howell 2003, Mossman 2017).

\section{Management as Services Provision}

For management to add value to the production process, it must ensure that tasks are ready for execution (Hamzeh et al., 2016, Koskela 2004). It is necessary to ensure all the preconditions identified by Koskela (2000) that must be the primary function of management as a service provider, see figures 2,3 , and 4 .

\section{MaNAGEMENT AS AN ORganization}

The organization's definitive objective must be to increase the people's reliability to delegate responsibilities. Before the occurrence of problems, these are solved by employing coordination at all levels. It is recommended to work with the Last Planner System (LPS) developed by Ballard (2000) but with the vision of Mossman (2017) and the management of commitments by Gamarra (2018).

\section{MANAGEMENT AS SELF-ORGANiZATION}

Can management, in certain aspects, generate more problems than it solves? (Bertelsen 2003a) "This leads to a new understanding where any worker should have the freedom to self-organize to execute the work. In the short term, the idea is to obtain optimal results by making the minimum possible control" (Gamarra 2018, p.44).

\section{PROPOSAL FOR A FLOW BASED CONSTRUCTION MANAGEMENT MODEL}

The proposed management model takes into account the management of flows. The complexity approaches for the management of construction projects described by Bertelsen and Koskela (2005), the VFO model proposed by Bertelsen (2017); and the seven preconditions de Koskela (2000), except for external conditions because they are a threat of flow, but not a flow in the proposed model.

\section{DESCRIPTION OF THE COMPONENTS OF THE MODEL}

- Project team: Represent all project stakeholders for the materialization of the project.

- Client: Represents the value of the final product.

- Suppliers: Represents the external team that provides materials, equipment, and tools.

- Crews: Represents the operational part of the project team (workers).

- Value Flow or Process: Represents the processes to be executed to obtain the product and be able to satisfy the client's value proposition. The evolution of the product. 
- Subject Flow or Operations: Represents the work of the operative part. It is where the interaction of labor and machinery with materials is generated, the workflow.

- Supply Flow: Represents the flow of resources for the execution of the project.

- Information Flow: Represents the transmission of information, at all levels, from the value proposition to the client for decisión making in the project.

- Layout Flow: Represents the distribution of space in the project, changing as the project's execution is carried out.

- Cost Flow: Represents the client's competence around the project's cash flow.

\section{DESCRIPTION OF THE FLOW-BASEd MANAGEMENT MODEL}

The management model is explored in 3 levels: strategic, tactical, and operational.

At the strategic level seeks, in advance, to manage the flows for the execution of the products or final deliverables (for example, in the finishing phase of a multi-family building project, products can be basements, departments, common areas, facade), defined by the project team based on the client's value proposition.

The client's value proposition leads to identifying the value flow (for example, related to the product department: kitchen, bedroom, bathroom, living room, and others). The progress of these (until reaching the final product) is what represents the operations or workflow (for example, for the finished kitchen: pre-finished paint, floor and wall veneer, furniture, electrical appliance, granite countertops, sanitary appliances, windows, doors, and others)

At this level, the value flow is the critical flow (Bertelsen et al. 2006), the most important, and is fed by the others. It is necessary to decide how these will be executed to define the operations (for example, everything changes if you choose to prefabricate). Also, it is essential to approve and validate the design (Gamarra 2018) and develop dates of compliance or milestones of the support flows, information, supply, layout, and cost. For example, it is closing dates with suppliers and subcontractors, associated payments, information required with specific dates, distribution of the project layout over time, cash flow, and others (See Figure 2).

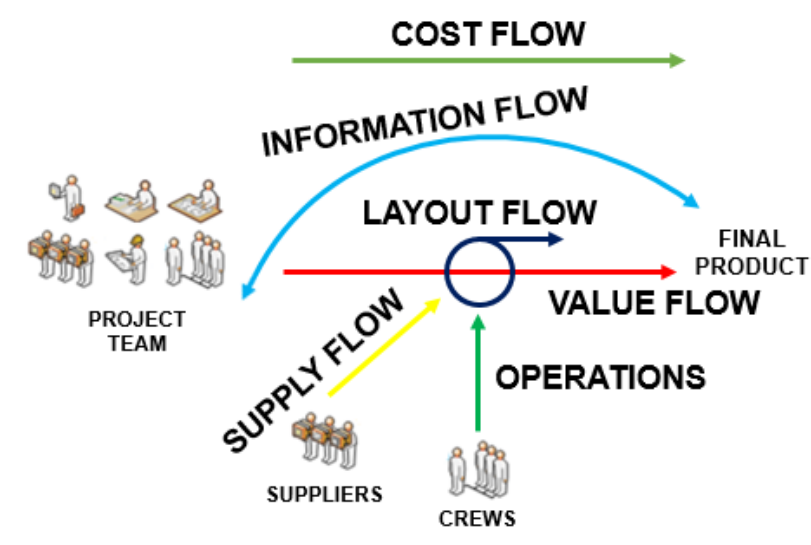

Figure 2: Flow management at a strategic level 
At the tactical level, the subject flow is the critical flow (See Figure 3). At this level, flow management seeks to ensure that new support flows meet the workflow requirements. To do this, the person responsible for the task must know everything about the operations. Before executing the task, the person responsible should identify preconditions, defined by Koskela (2000), related to the tasks and ensure that preconditions are ready to execute (Gamarra 2018).

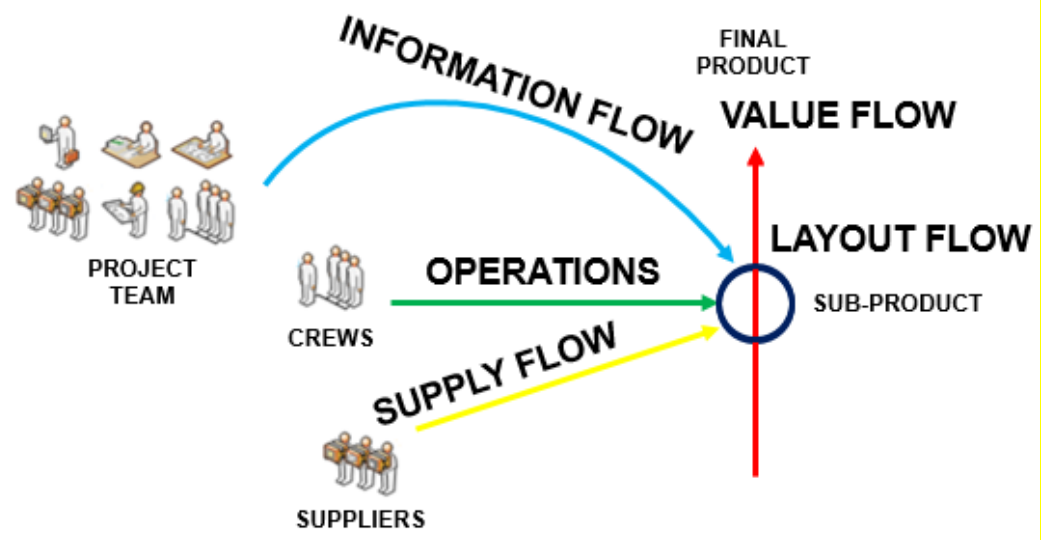

Figure 3: Flow management at the tactical level

Finally, the tasks would be ready to be executed (Hamzeh et al., 2016). Since the flows at the higher levels were already managed, it would only suffice to verify the preconditions for each task (Gamarra 2018).

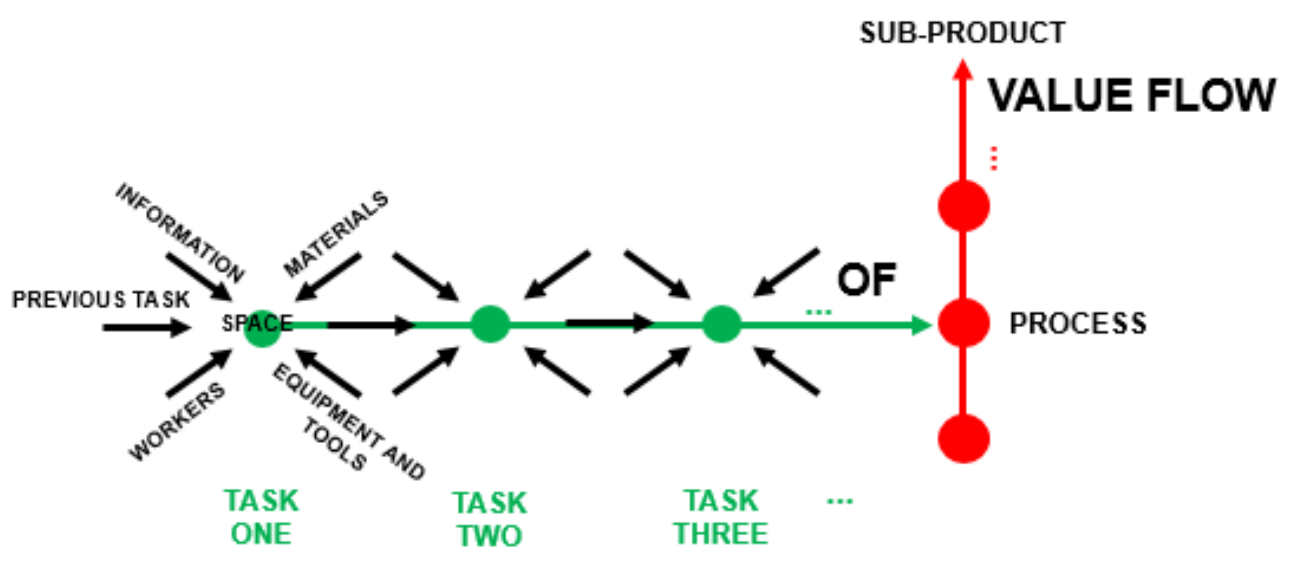

Figure 4: Flow management at the operational level

\section{ORGANIZATION FOR THE MANAGEMENT OF CONSTRUCTION BASED ON FLOWS}

\section{Complex Adaptive System (CAS)}

Getting out of control is a characteristic of complex systems, but adaptability is also part of their nature. These systems can stabilize on their own. 
"This can be seen as an important characteristic in the management perspective, since once the system has been established in a stable situation, it will probably remain there for a long time, which will encourage cooperation and, therefore, efficiency" (Bertelsen and Koskela 2005, p.7)

So, why not see the production system under construction as a Complex Adaptive System (CAS)? Authors believe that the desired stability can be achieved by developing an Operational Excellence Organization.

\section{OPERATIONAL EXCELLENCE (OPEX)}

Operational Excellence (OPEX) is the relationship between an organization's results and behavior based on principles. It is the consequence of ideal behavior, based on principles, to build a lasting excellence culture (Plenert 2018). The maturity of an organization concerning its learning, evolution, and sustainability (Shingo 1988).

The first challenge will be for the organization to define its basic principles. All those who are part of the organization must recognize these principles. Each person is expected to understand and commit to a culture that reflects behavior based on principles. These will be carried out sequentially, with continuous learning, and in an adaptative way, for which it will be necessary that everything developed is part of knowledge management.

\section{DISCUSSION AND CONCLUSIONS}

The proposed model offers the possibility of a holistic analysis of the production system under construction, considering flow management as a basis.

Although the Transformation - Flow - Value (TFV) model offers a good representation of the production system, this model focuses on the workflow and the flow of subjects for Shingo (1988). It does not achieve to cover an integral view of the system. By contrast, a flow model represents it better. The definition of flow as a "chain of events" offers the possibility of holistic analysis. An excellent initial proposal and little disclosed was the Value - Flow - Operation (VFO) model. This research proposes representing the preconditions of Koskela (2000) as flows in three different levels and prioritizing the location for each task characterized by the layout flow. Construction's nature must be managed based on the production location (Kenkey and Seppänen 2010).

The importance of the flows lies in being the main components of production under construction. Therefore, it is necessary to generate and manage flows and identify their role within the system and current events' chains. On the other hand, it is considered appropriate to change the paradigm of identifying constraints by the risk management of the flow at all levels, again see figures 2,3 , and 4 . A first attempt to manage risk focuses on paying particular attention to the enemies of the flow: Mura, Muri, and Muda.

An integral vision of the production system allows us to observe that it covers the project, industry, social aspect, people, and interrelation established in an organization. The perspectives and approaches of complexity open a new panorama in construction management, showing the people's importance and influence.

This research proposes to manage complexity by understanding and promoting the production system as a Complex Adaptive System (CAS), where Operational Excellence $(\mathrm{OPEX})$ is the main engine to create culture and organizations of action. 


\section{RECOMMENDATIONS AND FUTURE RESEARCH LINES}

The authors recommend carrying out future investigations of each of the flows described in the proposal of the management model. All are equally important, but concerning which flow the project team wants to optimize, following the publication of Bertelsen et al. (2006), the team should consider this a critical flow within the model and perform the respective study.

On the other hand, the management based on flows is compatible with the LocationBased Management System (LBMS) because it requires the location for its graphic demonstration (Kenkey and Seppänen 2010). Authors consider that the flow line diagram is the value flow map for construction.

Finally, future research should aim for Operational Excellence (OPEX). The authors recommend following Shingo's ideas transmitted in Plenert (2018).

\section{REFERENCES}

Bertelsen, S. (2003a)."Complexity-Construction in a new Perspective". Proceedings of the $11^{\text {th }}$ annual conference, International Group for Lean Construction, Blacksburg, Virginia, U.S.A., July, 2003.

Bertelsen, S. (2003b). "Construction as a Complex System". Proceedings of the $11^{\text {th }}$ annual conference, International Group for Lean Construction, Blacksburg, Virginia, U.S.A., July, 2003.

Bertelsen, S. (2017). The Unruly Project. USA: Sven Bertelsen aps, pp. 13-81.

Bertelsen, S. and Emmitt, S. (2005). "The client as a Complex System". Proceedings of the $13^{\text {th }}$ annual conference, International Group for Lean Construction, Sydney, Australia, July, 2005.

Bertelsen, S. and Koskela, L. (2005): "Approaches to Managing Complexity in Construction Project Production". Becon: $1^{\text {st }}$ International Conference on Built Environment Complexity, Reino Unido.

Berltesen, S., Koskela, L., Henrich, G. and Rooke, J. (2006). "Critical Flow - Towards a Construction Flow Theory". Proceedings of the $14^{\text {th }}$, International Group for Lean Construction, Santiago, Chile.

Drevland, F. and Tillmann, P. (2018). "Value for Whom?". Proceedings of the $26^{\text {th }}$ annual conference, International Group for Lean Construction, Chennai, India, July, 2018.

Erikshammar, J., Björnfot, A., Gardelli, V. (2018). "The Ambiguity of value". Proceedings of the $26^{\text {th }}$ annual conference,International Group for Lean Construction, Chennai, India, July, 2018.

Gamarra, G. (2018). Gestión de Compromisos de Subcontratistas para el Levantamiento de Restricciones en Procesos Incidentes de Acabados en Proyectos de Edificaciones Civiles. [Management of Subcontractors Commitments for Removing Constraints in Processes Incidents of Finishings in Projects of Civil Buildings] BSc. National University of Engineering, Perú, pp.29, 44, 73-92.Available at: http://cybertesis.uni.edu.pe/handle/uni/15744. 
Hamzeh, F., Zankoul E. and El Sakka, F. (2016). "Removing Constraints to Make Tasks Ready in Weekly Work Planning". Creative Construction Conference, Budapest, Hungary.

Kalsas B.T. and Bølviken T. (2010). "The Flow of Work In Construction: A Conceptual Discussion". Proceedings of the $26^{\text {th }}$ annual conference, International Group for Lean Construction, Chennai, India, July, 2018.

Kenley, R. and Seppänen, O. (2010). Location-based Management for Construction: Planning, Scheduling and Control. London and New York: Spon Press, pp. 387-408.

Koskela, L. (1992). Application of the New Production Philosophy to Construction. CIFE Technical Report \#72, Stanford University, Finlandia, pp.11-16.

Koskela, L. (2000). An Exploration Towards a Production Theory and its Application to Construction. PhD Diss, University of Technology, VTT Building Technology, Espoo, Finland, pp. 87-106.

Koskela, L. (2004). "Making do - The Eighth Category of Waste". Proceedings of the $12^{\text {th }}$ annual conference,International Group for Lean Construction, Helsing $\varnothing$, Denmark.

Koskela, L. and Howell, G. (2002). The underlying theory of project management is obsolete. Project Management Institute, USA.

Koskela, L., Rooke, J., Bertelsen, S., and Henrich, G. (2007). "The TFV Theory of Production: New Developments". Proceedings of the $15^{\text {th }}$ annual conference, International Group of Lean Construction, East Lansing, Michigan, USA, July, 2007.

Kraemer, K., Koskela, L. and Kagioglou, M. (2007). "How Construction Flows Have Been Understood in Lean Construction". Proceedings of $4^{\text {th }}$ International Research Symposium (SCRI), University of Salford, UK.

Macomber, H. and Howell, G. (2003). "Linguistic Action: Contributing to the Theory of Lean Construction". Proceedings of the $11^{\text {th }}$ annual conference, International Group for Lean Construction, Blacksburg, Virginia, U.S.A., July, 2003.

Mossman, A. (2017). Last Planner ${ }^{\circledR}$ : 5+1 Crucial \& Collaborative Conversations for Predictable Design \& Construction Delivery. The Change Business Ltd, pp.13-30.

Plenert, G. (2018). Discover Excellence - An Overview of the Shingo Model and Its Guiding Principles.Boca Raton, FL:Taylor \& Francis Group, CRC Press, pp.27-54.

Ramirez, R. (2014). Metodología para la Mejora Continua (Shingo) del Sistema de Construcción con Prefabricados de Concreto. [Methodology for the Continuos Improvement (Shingo) of the Construction System with Prefabricated Concrete]. BSc. National University of Engineering, Perú, pp. 27, 95-111. Available at: http://cybertesis.uni.edu.pe/handle/uni/4398.

Shingo, S. (1988) Non-Stock Production: The Shingo System of Continuous Improvement. Cambridge, USA: Productivity Press,pp.4-5, 84-90. 